\title{
Gambaran Derajat Dismenore dan Upaya Mengatasinya di Pondok Pesantren Darussalam Al-Hafidz Kota Jambi
}

\author{
Ria Febrina \\ Prodi DIII Kebidanan STIKes Biturrahim Jambi, Indonesia \\ Email: febrinaria2002@gmail.com.
}

Submitted : 03/12/2020

Accepted: 21/1/2021

Published: 06/03/2021

\begin{abstract}
Dysmenorrhea is a menstrual disorder that is often experienced by young women. Dysmenorrhoea is characterized by lower abdominal pain and may be accompanied by other symptoms. The incidence of dysmenorrhea in Indonesia consists of primary dysmenorrhea $54.89 \%$ and secondary dysmenorrhea 9.36\%. Dysmenorrhea can have a negative impact on young women, namely disruption in teaching and learning activities so that it will affect academic or academic achievement. This study is to describe the degree of dysmenorrhea and the efforts to overcome it in the Darussalam Al-Hafidz Islamic Boarding School, Jambi City. This type of quantitative research with a descriptive design. Respondents who have experienced dysmenorrhea as many as 31 respondents were sampled in this study.The data collection technique was done by filling out a questionnaire. The data is presented in a frequency distribution table. The results of the study most of the respondents experienced a degree of mild pain dysmenorrhea as many as $80.6 \%$ of respondents, most of the efforts to treat dysmenorrhea by non-pharmacological means by applying balsam or lotion as much as 71.0\%. Most of the respondents experienced mild pain dysmenorrhea and Most of the efforts to treat dysmenorrhea are non-pharmacological by applying balsam or lotion.
\end{abstract}

Keywords: dysmenorrhea, menstrual disorders, teenage girl.

\begin{abstract}
Abstrak
Dismenore merupakan gangguan menstruasi yang sering dialami oleh remaja putri. Dismenore ditandai dengan nyeri perut bagian bawah dan dapat disertai gejala lainnya. Angka kejadian dismenore di Indonesia terdiri atas dismenore primer 54,89\% dan dismenore sekunder 9,36\%. Dismenore dapat memberikan dampak yang buruk bagi remaja putri yaitu menimbulkan gangguan dalam kegiatan belajar mengajar sehingga akan berpengaruh pada prestasi di bidang akademik maupun non akademik. Penelitian ini untuk mendeskripsikan derajat dismenore dan upaya penanggulangannya di Pondok Pesantren Darussalam Al-Hafidz Kota Jambi. Jenis penelitian kuantitatif dengan desain deskriptif. Responden yang pernah mengalami dismenore sebanyak 31 responden dijadikan sampel dalam penelitian ini. Teknik pengumpulan data dilakukan dengan pengisian kuesioner. Data disajikan dalam tabel distribusi frekuensi. Hasil penelitian sebagian besar responden mengalami derajat nyeri ringan dismenore sebanyak $80,6 \%$ responden, sebagian besar upaya pengobatan dismenore secara non farmakologis dengan mengoleskan balsam atau lotion sebanyak $71,0 \%$. Sebagian besar responden mengalami nyeri dismenore dan nyeri ringan. Pengobatan dismenore sebagian besar bersifat non farmakologis dengan mengoleskan balsam atau losion.
\end{abstract}

Kata kunci: dismenore, gangguan menstruasi, remaja putri

\section{PENDAHULUAN}

Masa remaja (Adolescence) merupakan masa di mana terjadi transisi masa kanak-kanak menuju dewasa, biasanya antara usia 13 dan 20tahun, yang mengalami perubahan psikologis, kognitif, dan seksualitas. Anak usia sekolah mengalami perubahan mulai dari 6-18 tahun sangat luas dan mencakup seluruh area pertumbuhan dan perkembangan (Perry \& Potter 2009). Menurut World Health Organization (WHO) (2014), remaja adalah penduduk dalam rentang usia 10-19, dan masa remaja terbagi atas masa remaja awal (early adolescence) berusia 10-13 tahun, masa remaja tengah (middle 
adolescence) berusia 14-16 tahun dan masa remaja akhir (late adolescence) berusia 1719 tahun.

Pada masa remaja terjadi peristiwa yang sangat penting yaitu peristiwa pubertas. Peristiwa pubertas merupakan serangkaian peristiwayang mengarah kematangan seksual dengan terjadinya percepatan pertumbuhan, pematangan tulang rangka, perkembangan karakteristik seksual dan pencapaian fertilitas. Salah satu proses pematangan seksual yang terjadi pada remaja perempuan dalam masa pubertas ini adalah terjadinya menstruasi pertama/menarche (Norwitz and Schorge 2008).

Menstruasi adalah suatu proses yang normal, yang terjadi setiap bulannya pada hampir semua wanita.Menstruasi terjadinya pengeluaran darah, dalam jangka waktu 3-5 hari setiap bulannya (Wiknjosastro 2009). Pada saat menstruasi sering muncul keluhan, khususnya pada perempuan usia produktif. Keluhan ini tidak hanya mengganggu masalah kesehatan reproduksi, tetapi dapat juga mengganggu produktivitas perempuan sehari-hari.

Gangguan menstruasi yang sering dialami perempuan seperti nyeri perut bagian bawah, menstruasi yang tidak teraturnyeri pinggang, dan salah satunya yaitu dismenore (Kasdu, 2005). Dismenore merupakan nyeri perut bagian bawah yang terkadang rasa nyeri tersebut meluas hingga ke pinggang, punggung bagian bawah dan paha (Badziad, 2003). Ada tiga tingkat derajat dismenore, yaitu dismenore ringan, dismenore sedang, dan dismenore berat (Manuaba, 1999).

Menurut WHO dalam penelitian Yulita, dkk (2019), angka kejadian dismenore cukup tinggi di seluruh dunia. Rata-rata insidensi terjadinya dismenore pada wanita muda antara $16,8-81 \%$. Ratarata di negara Eropa dismenore terjadi pada 45-97\% wanita. Dengan prevalensi terendah di Bulgaria $(8,8 \%)$ dan tertinggi mencapai $94 \%$ di negara Finlandia. Di
Amerika Serikat, dismenore diakui sebagai penyebab paling sering ketidakhadiran di sekolah yang dialami remaja putri. Angka kejadian dismenore di Indonesia sebesar $54,89 \%$ dismenore primer dan 9,36\% dismenore sekunder.

Dismenore ringan terjadi di skala nyeri $1-4$, dismenore sedang terjadi di skala nyeri 5-6, dan dismenore berat terjadi pada skala nyeri 7-10 (Leppert 2004). Dismenore dibedakan menjadi dismenore primer dan dismenore sekunder. Dismenore primer terjadi pada 6-12 bulan setelah menarche dan berlanjut hingga usia 20-an, dismenore primer disebabkan karena tingginya kadar prostaglandin. Sedangkan dismenore sekunder merupakan nyeri menstruasi yang disebabkan oleh keadaan patologi dari pelvik atau uterus, dapat terjadi setiap waktu setelah menarche dan ditemukan pada usia 25-33 tahun (Dewi 2012).

Dismenore juga memberikan dampak yang buruk bagi remaja putri, yaitu menimbulkan gangguan dalam kegiatan belajar mengajar, tidak memperhatikan penjelasan yang diberikan oleh guru, dan kecenderungan tidur di kelas saat kegiatan belajar mengajar. Ini berpengaruh pada prestasi dibidang akademik maupun non akademik.Banyak remaja yang mengeluh bahkan tidak mau masuk sekolah pada saat menstruasi. Semakin berat derajat nyeri yang dialami maka aktivitas belajarnya pun semakin terganggu (Iswari et al. 2014).

Dampak yang paling banyak dirasakan karena dismenore adalah keterbatasan aktivitas fisik, isolasi sosial, konsentrasi yang buruk, dan ketidakhadiran dalam proses belajar mengajar (Farotimi et al. 2015). Perilaku dalam mengatasi nyeri dismenore pada remaja dapat dilakukan dengan beberapa cara, diantaranya pergi ke rumah sakit, pusat kesehatan masyarakat, dokter pribadi, mengonsumsi obat herbal, minum obat dari toko terdekat, kompres hangat, dan beristirahat (Gustina and Djannah 2017). 
Penelitian yang dilakukan oleh (Anisa Wulandari, Hasanah, and Woferst 2012) yang dilakukan pada siswi SMP di Kecamatan Lima Puluh Koto Pekan Baru (rentang usia 12-14 tahun) didapatkan sebagian besar responden mengalami dismenore pada tingkat nyeri sedang (48, 1\%). Penelitian Yulita, dkk (2019) sebagian besar siswi SMA Negeri Purwodadi Sumatera Selatan mengalami nyeri dismenore sedang sebanyak 33 siswi $(68,8 \%)$.

Berdasarkan studi pendahuluan yang dilakukan oleh penulis di Pondok Pesantren Darussalam Al-Hafidz Kota Jambi pada 10 siswi terdapat 8 siswi sering mengalami nyeri haid. Ketika studi pendahuluan, peneliti juga melakukan wawancara kepada 8 siswi yang mengalami masalah dismenore dan menanyakan upaya penanganan yang dilakukan ketika merasakan nyeri menstruasi yang dialami siswi.

Tujuan penelitian ini adalah untuk mengetahui gambaran derajat dismenore dan upaya mengatasinya di Pondok Pesantren Darussalam AL-Hafidz Jambi.

\section{METODE PENELITIAN}

Jenis penelitian ini adalah kuantitatif dengan desain deskriptif. Populasi dalam penelitian ini adalah siswi kelas $\mathrm{X}, \mathrm{Xi}$ dan XII yang pernah mengalami dismenore berjumlah 31 orang. Sampel dalam penelitian ini adalah Semua responden yang mengalami dismenore. Analisis data menggunakan SPSS analisis univariat untuk mengetahui distribusi frekuensi derajat dismenore masing-masing siswi dan untuk mengetahui upaya penanganan dismenore secara farmakologi dan non farmakologi.

\section{HASIL DAN PEMBAHASAN Gambaran Usia}

Berdasarakan hasil penelitian, didapatkan gambaran usia sebagai berikut :

\section{Tabel 1 Distribusi frekuensi usia pada siswi yang mengalami dismenore}

\begin{tabular}{lll}
\hline $\begin{array}{c}\text { Usia } \\
\text { Remaja }\end{array}$ & $\begin{array}{c}\text { Frekuen } \\
\text { si }\end{array}$ & \multicolumn{1}{c}{$\begin{array}{c}\text { Persentase } \\
(\%)\end{array}$} \\
\hline 16 & 22 & 71.0 \\
17 & 6 & 19.4 \\
18 & 2 & 6.5 \\
19 & 1 & 3.2 \\
Total & 31 & 100.0 \\
\hline
\end{tabular}

Usia responden sebagian besar berada pada usia 16 tahun sebanyak 22 responden (71\%).

Rata-rata usia yang mengalami dismenore di Pondok Pesantren Darussalam Alhafidz yaitu berumur 16 tahun sebanyak $22(70 \%)$ responden. Menurut Depkes (2009) bahwa usia remaja dengan rentang 12-16 tahun merupakan kategori masa remaja awal. Masa remaja awal ditandai dengan hampir lengkapnya pertumbuhan pubertas, timbulnya ketrampilanketrampilan berpikir yang baru, peningkatan pengenalan terhadap datangnya masa dewasa dan keinginan untuk meningkatkan jarak emosional dan psikologis dengan orang tua (Rukmini, 2004).

Hasil yang didapat dalam penelitian sesuai dengan penelitian Rakhma (2012) di SMK Arjuna Depok Jawa Barat bahwa mayoritas usia remaja putri tingkat SMA adalah 15.9 tahun. Hal ini sesuai dengan teori menurut Pearce dalam buku Proverawati (2009) bahwa permulaan menstruasi pada seorang gadis pada masa pubertas, yang biasa muncul pada usia 1114 tahun.

\section{Gambaran Derajat Menstruasi}

Berdasarkan hasil penelitian didapatkan distribusi frekuensi derajat menstruasi sebagai berikut : 
Tabel 2 Distribusi frekuensi derajat menstruasi pada siswi yang mengalami dismenore

\begin{tabular}{lcc}
\hline $\begin{array}{l}\text { Derajat } \\
\text { Dismenore }\end{array}$ & Frekuensi & $\begin{array}{c}\text { Persentase } \\
(\boldsymbol{\%})\end{array}$ \\
\hline Nyeri Ringan & 25 & 80.6 \\
Nyeri Sedang & 4 & 12.9 \\
Nyeri Berat & 2 & 6.5 \\
Total & 31 & 100.0 \\
\hline
\end{tabular}

Sebagian besar responden mengalami derajat dismenorhe dengan nyeri ringan sebanyak 25 (80.6) responden.

\section{Gambaran Upaya Penanganan dismenore dengan non farmakologi \\ Berdasarkan hasil didapatkan distribusi frekuensi upaya penanganan dismenorhe dengan non farmakologi sebagai berikut : \\ Tabel 3 Distribusi frekuensi upaya penanganan dismenore dengan non farmakologi pada siswi yang mengalami dismenore}

\begin{tabular}{lcc}
\hline $\begin{array}{c}\text { Upaya Penanganan } \\
\text { Dismenore }\end{array}$ & Frekuensi & $\begin{array}{c}\text { Persentase } \\
(\%)\end{array}$ \\
\hline Menarik nafas dalam & 19 & 61.3 \\
Teknik distraksi & 15 & 48.4 \\
Kompres hangat & 14 & 45.2 \\
Mandi dengan air hangat & 9 & 29.0 \\
Ramuan herbal & 11 & 35.5 \\
Teknik guided imagery & 15 & 48.4 \\
Mengolesi balsam atau & 22 & 71.0 \\
lotion & & \\
Melakukan Pemijatan & 14 & 45.2 \\
Melakukan posisi knee & 19 & 61.3 \\
chest & & \\
Olah raga & 9 & 29.0 \\
Beristirahat atau tidur & 20 & 64.5 \\
Berzikir & 1 & 3.2 \\
\hline
\end{tabular}

Upaya penanganan dismenore dengan cara non farmakologi bahwa yang dilakukan oleh responden yaitu sebanyak $22(71 \%)$ responden mengolesi balsem atau lotion, $20 \quad(64.5 \%)$ responden beristirahat atau tidur, 19 (61.3\%) responden menarik napas dalam dan melakukan posisi knee chest, 17 (54.8\%) responden melakukan teknik distraksi, 15
(48.4\%) melakukan teknik guided imagery, $14(45.2 \%)$ responden menggunakan kompres hangat dan melakukan pemijatan, $11(35.5 \%)$ menggunakan ramuan herbal, 9 (29 \%) responden melakukan mandi air hangat dan olah raga, 1 (3.2\%) reponden melakukan dengan berzikir.

Sebagian besar responden melakukan upaya penanganan dismenore dengan upaya mengolesi perut menggunakan balsam atau lotion. Hal ini didukung oleh teori yaitu pengompresan dengan air hangat, ketika nyeri menstruasi datang, lakukan pengompresan menggunakan air hangat di perut bagian bawah karena dapat membantu merilekskan otot-otot dan sistem saraf. Selain itu mandi air hangat dan mengolesi bagian yang nyeri dengan balsem atau lotion penghangat dapat juga dilakukan untuk menurunkan nyeri. Respon fisiologis yang ditimbulkan dari teknik ini adalah vasodilatasi atau pelebaran pembuluh darah, sehingga dapat meningkatkan aliran darah ke bagian tubuh yang sakit dan mampu menurunkan viskositas yang dapat mengurangi ketegangan otot,dengan respon tersebut dapat meningkatkan relaksasi otot dan menurunkan nyeri (Bobak, 2005).

Melakukan upaya penanganan dismenore dengan istirahat atau tidur merupakan salah satu upaya yang banyak dilakukan dalam menghadapi dismenore pada remaja putri di Pondok Pesantren Darusslaam Al-Tahfidz.Hasil penelitian Rakhma (2012) dari 129 responden terdapat 60 siswi melakukan upaya dismenore dengan melakukan istirahat atau tidur. Didukung oleh teori menurut Hidayat (2008) istirahat merupakan keadaan relaks tanpa adanya tekanan emosional, bukan hanya keadaan tidak beraktivitas tetapi juga kondisi yang membutuhkan ketenangan.

Sebanyak 19 reponden (61.3\%) melalukan upaya mengatasi dismenore dengan menarik napas dalam, hal ini sesuai dengan teori bagwa teknik menarik nafas dalam yaitu menarik nafas dalam dari hidung dan perlahan-lahan udara 
dihembuskan melalui mulut.Hal ini dapat meningkatkan oksigenasi darah, menurunkan intensitas nyeri dan menurunkan kecemasan (Smeltzer, 2002). Didukung oleh hasil penelitian Dwi Haryanti (2018) teknik napas dalam dapat menurunkan dismenore dari skala nyeri sedang menjadi skala nyeri ringan pada remaja putri di Praktik Mandiri Bidan Wiwik Ismurtini Sempor.

Sebanyak 19 responden (61.3) melakukan upaya mengatasi dismenore dengan melakukan posisi knee chest. Sejalan dengan hasil penelitian Endah (2016) upaya yang dilakukan untuk mengatasi dismenore dengan melakukan posisi knee chest sebesar $71.05 \%$. hal ini sesuai dengan teori melakukan posisi knee chest, yaitu menelungkupkan badan di tempat yang datar, lutut ditekuk dan didekatkan ke dada.Posisi knee chest dapat menggerakkan otot, maka otot menjadi lebih kuat dan elastic secara alami sehingga melenturkan otot-otot pada pelvis dan membantu kelancaran peredaran darah maka meningkatkan relaksasi otot dan menurunkan nyeri (Akatri, 1996).

Sebanyak 15 responden $(48,4 \%)$ melakukan upaya penanganan dismenore dengan melakukan teknik distraksi diantaranya dengan mendengarkan sholawat/musik, dan membaca buku. Hal ini sesuai dengan teori bahwa teknik distraksi merupakan teknik pengalihan fokus perhatian terhadap nyeri ke stimulasi lain. Distraksi juga dapat menurunkan nyeri, menurunkan persepsi nyeri dengan stimulasi nyeri yang ditransmisikan ke otak. Keefektifan distraksi tergantung pada kemampuan pasien untuk menerima dan membangkitkan input sensori selain nyeri (Smeltzer, 2002). Didukung oleh penelitian Prasanti (2017) menyatakan bahwa terdapat pengaruh metode distraksi mendengarkan music terhadap penurunan derajat nyeri dismenore primen pada siswi SMP Negeri 1 Jaten.
Sebanyak 15 responden $(48,4 \%)$ melakukan upaya mengatasi disminore dengan teknik guided imagery. Teknik guided imagery merupakan pengalaman sensori buatan yang dapat menurunkan persepsi nyeri secara efektif dan menurunkan reaksi terhadap nyeri. Teknik ini dapat dilakukan dengan membayangkan pengalaman yang menyenangkan dari memori, mimpi, fantasi dan penglihatan, dengan berfokus kepada pengalaman yang dibayangkan, klien dapat mengubah persepsinya terhadap nyeri yang dialami (Akatri, 1996). Hal ini didukung oleh penelitian Hera \& nicky (2019) menyatakan bahwa ada pengaruh pemberian guided imagery terhadap penurunan nyeri dismenore pada mahasiswa Program Studi D III Kebidanan STIKES Kurnia Jaya Persada Tahun 2017.

Sebanyak 14 responden $(45,2 \%)$ melakukan upaya mengatasi dismenore dengan melakukan kompres hangat. Pengompresan dengan air hangat di perut bagian bawah dapat merelaksasi otot-otot dan system saraf, selain itu mandi air hangat dan mengolesi bagian yang nyeri dengan balsam atau lotion penghangat dapat juga dilakukan untuk menurunkan nyeri (Taruna, 2003). Hal ini sejalan dengan penelitian Asmita \& Tri (2017) hasil penelitian menyatakan kompres hangat dapat menurunkan tingkat nyeri dismenore pada siswi SMK Perbankan Simpang Haru Padang.

Sebanyak 14 responden $(45,2 \%)$ melakukan upaya mengatasi dismenore dengan melakukan pemijatan. Pemijatan dapat meminimalkan reaksi terhadap nyeri.Pemijatan merupakan bentuk aplikasi sentuhan dan pergerakan terhadap otot, tendon, dan ligament tanpa memanipulasi sendi.Tidak hanya menghalangi persepsi rangsang nyeri tetapi juga merelaksasikan kontraksi dan spasme otot karena dapat memperlancar sirkulasi darah (Smeltzer, 2002). Hal ini sejalan dengan penelitian Asri, dkk (2017) menyatakan bahwa 
endorphine massage dapat menurunkan nyeri dismenore pada mahasiswi Jurusan Kebidanan Poltekkes Kemenkes Tasikmalaya.

Sebanyak 11 responden $(35,5 \%)$ melakukan upaya mengatasi dismenore dengan menggunakan ramuan herbal. Pengobatan herbal, nyeri haid dapat diatasi dengan minum jamu. Jamu nyeri haid yang sering digunakan banyak mengandung simpliasi yang berkhasiat sebagai anti nyeri, anti radang, serta anti spasmodic (anti kejang otot). Simplia dapat diperoleh di bumbu dapur, misalnya kunyit, buah asam, dan kayu manis. Pembuatannya akan diolah seperti jamu ( Wijayakusuma, 2008). Hal ini didukung oleh penelitianl penelitian Susilawati Reza (2017) menyatakan bahwa terdapat pengaruh pemberian minuman kunyit asam terhadap penurunan intensitas dismenore pada mahasiswi Poltekkes Kemenkes Malang Program Studi D III Kebidanan Jember.

Sebanyak 9 responden (29\%) melakukan upaya mengatasi dismenore dengan berolahraga. Olahraga teratur, melakukan olah raga dapat meningkatkan efisiensi kerja paru, meningkatkan efisiensi kerja jantung, meningkatkan jumlah dan ukuran pembuluh-pembuluh darah yang menyalurkan darah ke seluruh tubuh, meningkatkan volume darah sehingga oksigen dapat tersalurkan ke pembuluhpembuluh darah di organ reproduksi yang saat dismenore terjadi vasokontriksi. Olahraga juga dapat meningkatkan pelepasan endorphin (penghilang nyeri alami) ke dalam aliran darah. Frekuensi latihan olahraga dilakukan 3 kali dalam seminggu dengan durasi 30 sampai 60 menit akan memberikan efek bagi kesehatan dan keburagan. Hal tersebut didukung oleh penelitian Melda (2015) yoga efektif dalam menurunkan nyeri dismenore.Begitu juga dengan penelitian yang dilakukan Nancy (2014) menyatakan senam dismenore terbukti berpengaruh dalam menurunkan dismenore pada remaja putri di SMP N 2 Siantan, Pontianak. Satu orang responden melakukan upaya mengatasi dismenore dengan berzikir. Didukung oleh teori bahwa seseorang yang merasakan nyeri mempraktekkan penanganan dengan pendekatan agama dan spiritual (religious coping) seperti berdo'a, mencari dukungan spiritual untuk mengatasi nyeri (Aziato dalam Lailatul, 2018). Hal ini sejalan dengan hasil penelitian Lailatul (2018) Bahwa religius coping mempengaruhi nyeri saat haid sebesar $90.7 \%$. Dismenore yang dialami remaja dapat berkurang atau mereda setelah penggunaan religious coping yang dimiliki

\section{Gambaran Upaya Penanganan \\ Dismenore dengan Farmakologi}

Berdasarkan hasil penelitian didapatkan distribusi frekuensi upaya penanganan dismenorhe dengan farmakologi sebagai berikut :

Tabel 4 Distribusi frekuensi upaya penanganan dismenore dengan farmakologi pada siswi yang mengalami dismenore di Pondok Pesantren Darussalam Al-Hafid

\begin{tabular}{ccc} 
Upaya & Frekuensi & $\begin{array}{c}\text { Persentase } \\
\text { Penanganan } \\
\text { Dismenore }\end{array}$ \\
\hline$\%)$
\end{tabular}

Obat warung

$\begin{array}{lll}\text { Feminax } & 3 & 9.7\end{array}$

Resep dokter

Asam mefenamat $\quad 2 \quad 6.5$

Berdasarkan tabel 4 distribusi frekuensi upaya penanganan dismenore dengan cara farmakologi bahwa yang dilakukan oleh responden yaitu sebanyak 2 (6.5\%) responden mengkonsumsi obat anti nyeri dari resep dokter yaitu asam mefenamat dan 3 (9.7\%) responden mengkonsumsi obat anti nyeri dari warung yaitu feminax.

Upaya penanganan dismenore dengan farmakologi pada siswi di Pondok Pesantren Al-Tahfidz dibagi menjadi dua bagian yaitu minum obat anti nyeri dari 
obat-obat warung (Feminax, Panadol, dll) dan minum obat anti nyeri dari resep dokter (Asetaminofem, asam mefenamat, aspirin, dll). Siswi yang mengkonsumsi obat-obat warung sebanyak 3 siswi, yaitu 3 siswi mengkonsumsi feminax sedangkan siswi siswi yang mengkonsumsi obat anti nyeri dari resep dokter sebanyak 2 siswi yaitu mengkonsumsi asam mefenamat.

Hasil penelitian Rakma (2012) sebanyak 16 siswi mengkonsumsi obat anti nyeri dari warung dan 4 siswi mengkonsumsi obat anti nyeri resep dokter.Obat tanpa resep dokter merupakan obat yang dapat dibeli secara bebas dan aman dikonsumsi bila mengikuti aturan pakai dan dosis yang tercantum dalam kemasan. Wikjosastro (2005) mengungkapkan pengunaan obat analgesic dapat digunakan sebagai terapi simtomatik dan dapat ditemukan di pasaran.

\section{Gambaran Upaya Penanganan \\ Dismenore dengan Derajat Dismenore} Berdasarkan hasil penelitian didapatkan gambaran upaya penanganan dismenore dengan derajat dismenore sebagai berikut:

Tabel 5 Distribusi frekuensi upaya penanganan dismenore dengan farmakologi pada siswi yang mengalami dismenore

\begin{tabular}{lcccccccc}
\hline Upaya penanganan & \multicolumn{2}{c}{$\begin{array}{c}\text { Derajat nyeri } \\
\text { ringan }\end{array}$} & \multicolumn{2}{c}{$\begin{array}{c}\text { Derajat nyeri } \\
\text { sedang }\end{array}$} & \multicolumn{2}{c}{$\begin{array}{c}\text { Derajat nyeri } \\
\text { berat }\end{array}$} & \multicolumn{2}{c}{ Total } \\
& F & \% & F & \% & F & \% & F & \% \\
\hline Nafas dalam & 14 & $45.2 \%$ & 3 & $9.7 \%$ & 2 & 6.5 & 19 & 61.3 \\
Teknik distraksi & 13 & 41.9 & 1 & 3.2 & 3 & 9.7 & 15 & 48.4 \\
Kompres & 10 & 32.3 & 3 & 9.7 & 1 & 3.2 & 14 & 45.2 \\
Mandi air hangat & 8 & 25.8 & 0 & 0 & 1 & 3.2 & 9 & 29.0 \\
Herbal & 8 & 25.8 & 2 & 6.5 & 1 & 3.2 & 11 & 35.5 \\
Guided Imagery & 13 & 41.9 & 1 & 3.2 & 1 & 3.2 & 15 & 48.4 \\
Balsam/lotion & 16 & 51.6 & 4 & 12.9 & 2 & 6.5 & 22 & 71.0 \\
Pemijatan & 11 & 35.5 & 1 & 3.2 & 2 & 6.5 & 14 & 45.2 \\
Knee chest & 14 & 45.2 & 3 & 9.7 & 2 & 6.5 & 19 & 61.3 \\
Olah raga & 7 & 22.6 & 1 & 3.2 & 1 & 3.2 & 9 & 29.0 \\
Istirahat total & 15 & 48.4 & 4 & 12.9 & 1 & 3.2 & 20 & 64.5 \\
Lainnya & 1 & 3.2 & 0 & 0 & 0 & 0 & 1 & 3.2 \\
Minum obat warung & 0 & 0 & 1 & 3.2 & 2 & 6.4 & 3 & 9.7 \\
Minum obat dokter & 0 & 0 & 2 & 6.5 & 0 & 0 & 2 & 6.5 \\
\hline
\end{tabular}

Responden melakukan lebih dari 1 upaya penanganan dismenore

Berdasarkan tabel 5 distribusi frekuensi upaya penanganan dismenore dengan derajat dismenore bahwa responden yang mengalami derajat dismenore ringan sebagian besar melakukan upaya pemberian balsam atau lotion sebanyak $16(51.6 \%)$ responden, derajat dismenore sedang sebagian besar melakukan upaya penanganan dengan istirahat total dan pemberian balsam atau lotion sebanyak 4 (12.9\%) responden, derajat dismenore berat sebagian besar melakukan teknik distraksi sebanyak $3(9.7 \%)$ responden dan upaya penanganan dengan farmakologi sebagian besar responden mengkonsumsi obat warung sebesar $3(9.7 \%)$ responden.

Berdasarkan hasil crosstabulation bahwa siswi yang mengalami dismenore derajat nyeri ringan sebagian besar melakukan upaya pemberian balsam atau lotion sebanyak 16 (51.6\%) responden, derajat dismenore sedang sebagian besar melakukan upaya penanganan dengan istirahat total dan pemberian balsam atau 
lotion sebanyak 4 (12.9\%) responden, derajat dismenore berat sebagian besar melakukan teknik distraksi sebanyak 3 $(9.7 \%)$ responden dan upaya penanganan dengan farmakologi sebagian besar responden mengkonsumsi obat warung sebesar $3(9.7 \%)$ responden.

\section{SIMPULAN}

Sebagian besar responden mengalami derajat dismenore nyeri ringan dan sebagian besar upaya penanganan dismenore dilakukan dengan cara non farmakologi yaitu dengan cara mengolesi balsam atau lotion.

\section{SARAN}

Perlu diadakan penelitian lebih lanjut dengan variabel yang berbeda yang berkaitan dengan dismenore, seperti melihat pengaruh dismenore terhadap aktivitas belajar dan prestasi siswi, serta melakukan upaya penanganan dengan menggunakan metode yang lebih lengkap, seperti wawancara dan observasi.

\section{DAFTAR PUSTAKA}

Atikah, dkk. 2009. Menarche (Menstruasi Pertama Penuh Makna). Yogyakarta: Nuha Medika.

Badziad, A. 2003. Endokrionologi Dan Ginekologi Edisi Kedua. Jakarta: Media Aesculapius.

Bobak. 2004. Buku Ajar Keperawatan Maternitas Edisi Keempat. Jakarta: EGC.

Dahlan, A., \& Syahminan, Tri. 2017. Pengaruh Terapi Kompres Hangat terhadap Nyeri Haid (Dismenore) pada Siswi SMK Perbankan Simpang Haru Padang.

Dewi, N.S. 2012. Biologi Reproduksi. Yogyakarta: Pustaka Rihama.

Farotimi, A.A et al. 2015. "Knowledge, Attitude, and Healthcare-Seeking Behavior Towards Dysmenorrhea among Female Students of a Provate University in Ogun State, Nigeria."
Ournal of basic and clinical reproductive sciences 4 (1).

Gustina, T. 2015. Hubungan antara usia menarche dan lama menstruasi dengan kejadian dismenore primer pada remaja putri di SMK Negeri 4 Surakarta. Electronic These and Disertations Universitas Muhammadiyah Surakarta.

Gustina, E, \& S.N Djannah. 2017. "Impact of Dysmenorrhea and Health-Seeking Behavior among Female Adolescents." International Journal of Public Health Science 6 (2): 141-45.

Haryanti, Dwi. 2018. Penerapan Teknik Nafas Dalam terhadap Penurunan Nyeri Dismenore pada Remaja Putri di PMB Wiwik Ismurtini Sempor

Hidayat, A. Aziz Alimul. 2008. Riset Keperawatan Dan Teknik Penulisan Ilmiah. Jakarta: Salemba Medika.

Hidayati, K.R, dkk. 2016. Hubungan Antara Asupan Kalsium dan Asupan Zat Besi dengan Kejadian Dismenore pada Siswi di SMK Batik 2 Surakarta. Jurnal Kesehatan. Vol.1:2.

Iswari, D.P, Kadek, I Surianti, and G Mastini. 2014. "Hubungan Dismenore dengan Aktivitas Belajar Mahasiswa PSIK FK UNUD Tahun 2014." Community of Publishing in Nursing.

Kasdu, Dini. 2005. Solusi Problem Wanita Dewasa. Jakarta: Puspa Swara.

Leppert, Phyllis. 2004. Primary Care for Woman. Philadelphia: LippincottWilliam \& Wilkins.

Lowdermilk, D.L, et al. 2010. Maternity Nursing 8th Edition. St. Louis: Mosby Elsevier.

Manurung, Melda. 2015. Efektivitas Yoga terhadap Nyeri Dismenore Pada Remaja.

Musyafa'ah, Lailatul. 2018. Hubungan ANntara Religius Coping dengan Nyeri Saat Haid pada Remaja. Universitas Islam Negeri Sultan Syarif Kasim Riau.

Norwitz, E.R, \& J.O Schorge. 2008. At a 
Glance Obstetri Dan Ginekologi Edisi

2. Jakarta: Erlangga.

Perry \& Potter. 2009. Fundamental

Keperawatan Edisi 7. Jakarta:

Salemba Medika.

Prasanti, Destri Lisyam. 2017. Pengaruh

Metode DIstraksi Mendengarkan

Musik Terhadap Penurunan Nyeri

Dismenore Primer Siswi Negeri 1

Jaten. UniVersitas Sebelas Maret.

Racmah, Astrida. 2014. "Gambaran Derajat

Disemenore Dan Upaya Penangannya

Pa Siswi Sekolah Menengah Kejuruan

Arjuna Depok Jawa Barat." : 468-76.

Rahayu, A., dkk. 2017. Pengaruh Endorphine Massage terhadap Rasa

Sakit Dismenore pada Mahasiswa Jurusan Kebidanan Poltekkes

Kemenkes Tasikmalaya Tahun 2017.

Ramaiah. 2006. Mengatasi Gangguan

Menstruasi. Yogyakarta: Diglosia Medika.

Rumini, dkk. 2004. Perkembangan Anak Dan Remaja. Jakarta: Rineka Cipta.

Sinha, S, et al. 2016. "A Study of Menstrual Pattern and Prevalence of Dysmenorrhea during Menstruation among School Going Adolescenct Girls in Lucknow District, Uttar Pradesh, India." International journal of community medicine and public health 2 No.5: 1200-1203.

Smeltzer, Suzanne. 2002. Buku Ajar Keperawatan Medikal Bedah Edisi Delapan. Jakarta: EGC.

Sormin, Nancy, S. 2014. Efektivitas Senam DIsmenore dalam Mengurangi Dismenore pada Remaja Putri di SMP
N 2 Siantan Kabupaten Pontianak.

Utami, A.N, Ansar, J, \& SIdik, D. Faktor yang berhubungan dengan kejadian dismenore pada remaja putri SMA N 1Kahu Kabupaten Bone.

Tamsuri, A. 2003. Konsep Dan Penatalaksanaan Nyeri. Jakarta: EGC.

Tracey, Kelly. 2007. 50 Rahasia Alami Meringankan Sindrom Pramenstruasi. Jakarta: Erlangga.

Widyastuti. 2009. Kesehatan Reproduksi. Jakarta: Yayasan Bina Pustaka Sarwono Prawirohardjo.

Wiknjosastro, Hanifa. 2009. Ilmu Kandungan. Jakarta: Yayasan Bina Pustaka Sarwono Prawirohardjo.

Wulandari, A, and D Anurogo. 2011. Cara Jitu Mengatasi Nyeri Haid. Yogyakarta: CV Andi Offset.

Wulandari, Anisa, Oswati Hasanah, and Rismadefi Woferst. 2012. "Gambaran Kejadian Dan Manajemen Dismenore Pada Remaja Putri Di Kecamatan Lima Puluh Kota Pekanbaru." JOM Fkp 5 No.2.

Yoga, Ahimsa. 2010. "Pengaruh Kebiasaan Mengkonsumsi Minuman Kunyit Asam Terhadap Keluhan Dismenore Primer Pada Remaja Putri Di Kotamadya Surakarta."

Yusuf, Syamsu. 2009. Psikologi Perkembangan Anak Dan Remaja. Bandung: PT. Remaja Rosdakarya.

Yulita ES, dkk. 2019. Pengaruh Teknik Relaksasi Nafas Terhadap Dismenorea. Hasanuddin Journal of Midwifery. Vol 1:1. 